\title{
A Follow-up Study to Monitor Adult Height Among Spanish Children with Growth Hormone Deficiency Who Received Biosimilar Human Recombinant Growth Hormone (Omnitrope ${ }^{\circledR}$ ) During a Phase III Clinical Trial
}

Victoria Borrás Pérez • Juan Pedro López-Siguero • Gabriela Martínez • Raquel Corripio • Juan Manuel Fernández • Jose Ignacio Labarta • Marta Ferrer • Nuria Cabrinety • Pablo Prieto • Marta Ramón-Krauel · Jordi Bosch • Rafael Espino • Margarida Palla Garcia • Francisco Jose Rebollo

To view enhanced content go to www.advancesintherapy.com Received: November 24, 2014 / Published online: February 11, 2015

(c) The Author(s) 2015. This article is published with open access at Springerlink.com

\section{ABSTRACT}

Introduction: An initial Phase III clinical trial has evaluated the efficacy and safety of biosimilar recombinant human growth hormone (rhGH; Omnitrope $^{\circledR}$, Sandoz) in Spanish children with

Electronic supplementary material The online version of this article (doi:10.1007/s12325-015-0181-9) contains supplementary material, which is available to authorized users.

V. Borrás Pérez

Hospital General de Granollers, Barcelona, Spain

J. P. López-Siguero ( $\square)$

Hospital Universitario Carlos Haya, Málaga, Spain

e-mail: lopez.siguero@gmail.com

G. Martínez

Complejo Hospitalario de Jaén, Jaén, Spain

R. Corripio

Hospital de Sabadell, Corporació Universitaria Parc

Taulí, UAB, Barcelona, Spain

J. M. Fernández

Hospital Universitario San Cecilio, Granada, Spain

J. I. Labarta · M. Ferrer

Hospital Universitario Miguel Servet, Zaragoza, Spain

N. Cabrinety

Hospital Universitari Sagrat Cor, Barcelona, Spain growth hormone deficiency (GHD). At the end of the study, those patients still growing were offered to remain on treatment (as in usual clinical practice), and continued to be monitored. The aim of this study was to determine the adult height achieved by the Spanish children who participated in the initial Phase III clinical trial, and to evaluate the longterm safety of rhGH treatment.

P. Prieto

Hospital Universitario de Salamanca, Salamanca, Spain

M. Ramón-Krauel

Hospital San Joan de Deu, Universidad de Barcelona, Barcelona, Spain

J. Bosch

Hospital Universitario Arnau de Vilanova, Lérida, Spain

R. Espino

Hospital Universitario Nuestra Sra Valme, Seville, Spain

M. Palla Garcia · F. J. Rebollo

Sandoz Biopharmaceuticals, Madrid, Spain

e-mail: margarida.pallagarcia@sandoz.com 
Methods: This study was a multicenter, observational, retrospective follow-up study of patients who participated in the Phase III clinical trial (70 patients recruited). Auxological parameters [including height, height velocity, and their associated height standard deviation scores (HSDS)] were obtained from 39 patients. Safety was assessed by recording any adverse events (AEs).

Results: In total, 27 men and 12 women provided auxological data. At the start of the follow-up study, the mean age of the patients was $12.5 \pm 2.7$ years, mean height was $144.8 \pm 13.9 \mathrm{~cm}$ and mean HSDS was $-1.16 \pm 0.63$. By the end of the follow-up period, mean height had increased to $163.1 \pm 7.6 \mathrm{~cm} \quad(n=36 ;$ men $165.5 \pm 7.8 \mathrm{~cm}$, women $157.6 \pm 3.2 \mathrm{~cm}$ ) and mean HSDS also increased to $-1.01 \pm 0.59 \quad(n=36 ; \quad$ men $-1.07 \pm 0.52$, women $-0.86 \pm 0.72$ ). In terms of safety, no treatment-related AEs were reported during the study.

Conclusion: This cohort of Spanish patients with GHD showed a positive response to $\mathrm{rhGH}$ treatment, achieving adult height within the local normal ranges. In addition, rhGH treatment was well tolerated, with no new or additional safety concerns.

Keywords: Biosimilar; Growth hormone deficiency; Growth hormone treatment; Omnitrope ${ }^{\circledR}$; Somatropin

\section{INTRODUCTION}

The availability of recombinant human growth hormone (rhGH) since the late 1980s has revolutionized the treatment and long-term prognosis of children with growth hormone deficiency (GHD) and other growth disturbances $[1,2]$. In addition to near- normalization of final height, treatment with rhGH has been shown to improve pubertal development, bone mass, and quality of life in patients with GHD [3-5].

Currently, there are several rhGH products available for the treatment of pediatric growth disturbances. Omnitrope ${ }^{\circledR}$ (Sandoz) is the first product to be approved by the European Medicines Agency via the biosimilar regulatory pathway, with approval granted in 2006 on the basis of comparable quality, safety, and efficacy to the reference rhGH product (Genotropin ${ }^{\circledR}$, Pfizer) [6]. Biosimilar rhGH is licensed in Europe for the treatment of growth disturbances in the following pediatric indications: GHD, Turner Syndrome, chronic renal insufficiency, PraderWilli Syndrome, and children born small for gestational age [7].

The efficacy and safety of biosimilar rhGH has been extensively evaluated in several multicenter clinical trials, which have demonstrated comparable efficacy and safety to the reference product across pediatric indications [8-10]. Nonetheless, data on final height achieved following rhGH therapy are limited, particularly with biosimilar rhGH.

The original Spanish Phase III Omnitrope ${ }^{\circledR}$ study was an open-label, Phase III, multicenter, non-comparative study conducted across 19 participating centers [11]. The main objectives of the study were to examine the efficacy and safety of treatment with biosimilar rhGH in a group of GH-naïve pre-pubertal children [26 girls and 44 boys with a mean (SD) age of $8,7(2$, 4) years, respectively]. Sixty-eight patients had idiopathic GHD (66 with isolated GHD and 2 with multiple GHD) and 2 had organic GHD. GHD was diagnosed by the failure to achieve adequate serum $\mathrm{GH}$ levels $(10 \mathrm{ng} / \mathrm{mL})$ in two provocation tests (stimulation with insulin, L-dopa, glucagon, arginine, propranolol, and exercise, or clonidine). Eligible patients were 
treated with biosimilar rhGH (daily dose of $0.03 \mathrm{mg} / \mathrm{kg}$ body weight subcutaneously) for up to 5 years. The height, height standard deviation score (HSDS), and height velocity (HV) of the patients in the phase III Omnitrope ${ }^{\circledR}$ study entry were $118.7(12.5) \mathrm{cm}$, -2.98 (0.6), and $3.86 \quad(1.25) \quad \mathrm{cm} /$ year, respectively.

In that study [11], Omnitrope ${ }^{\circledR}$ treatment markedly improved pharmacodynamic parameters (insulin-like growth factor 1 and insulin-like growth factor binding protein 3), and elicited a good growth response, as demonstrated by significant increases from baseline in all auxological parameters evaluated. The safety profile of biosimilar rhGH was shown to be similar to the reference product, both in terms of adverse events (AEs) and immunogenicity [11].

This paper reports the efficacy and safety results of a long-term follow-up study of a subgroup of children with GHD treated with Omnitrope $^{\circledR}$ in the original phase III study [11] who were monitored until they achieved their adult height.

\section{METHODS}

\section{Study Design and Patient Population}

This was an observational, retrospective, multicenter, follow-up study examining the long-term safety and efficacy of Omnitrope ${ }^{\circledR}$ in patients recruited to a phase III study [11] and who continued rhGH treatment under the same participating investigators.

A total of 11 hospitals across Spain enrolled patients into this open-label extension study. Written informed consent was obtained from the patients or their legal representatives. The study was conducted according to the principles of the Declaration of Helsinki and adhered to the ICH Harmonized Guidelines for Good Clinical Practice. In addition, the study was monitored and approved by an Independent Ethics Committee.

The primary objective was to obtain and analyze data on the adult height. The secondary objectives were to ascertain the differences in height, HSDS, HV, and HV standard deviation score from when the phase III study was finalized until adult height was reached.

\section{Treatment and Visits}

The rhGH was administered subcutaneously in accordance with the Summary of Product Characteristics, the local prescribing information, and the standard clinical practice of each center. The patients continued treatment until they reached final height, or until rhGH treatment was interrupted or discontinued due to other reasons. The frequency of visits was at the discretion of the investigators; no additional or specific visits, tests, or assessments were required as part of the study.

\section{Efficacy Assessments}

Patients' height was measured at each visit, using a stadiometer (Holtain) by trained health staff and according to standard clinical practice. HV (cm/year) and HSDS were calculated using historical height data. In addition, the projected final height $\left(\mathrm{FH}_{\mathrm{pro}}\right)$ was defined as the height that the patient is expected to reach at the end of linear growth. In the original study, major increases in $\mathrm{FH}_{\text {pro }}$ during rhGH therapy were observed for both genders: all $\mathrm{FH}_{\text {pro }}$ values increased significantly when compared with the start of treatment [11]. 


\section{Safety Assessments}

All AEs were recorded at each visit for the complete duration of rhGH treatment, irrespective of causality. AEs were coded according to the Medical Dictionary for Regulatory Activities (MedDRA), Version 14.0 or higher.

\section{Data Collection and Analysis}

Patient data were recorded by the investigators in a case report form at each routine visit. All concomitant conditions and medications were also recorded. The frequency of visits was done as per usual clinical practice. Data from patients who discontinued treatment before reaching adult height were retained and included in all analyses.

Absolute frequencies are reported as a summary ( $n$ ) and relative frequencies as a percentage (\%); 95\% confidence intervals (CI) are also given. The 'normality' of quantitative variables was checked with the KolmogorovSmirnov test; normally distributed variables were then summarized using the mean and standard deviation (SD). For 'abnormal' variables, the median and the interquartile ranges are presented. The Chi-square or Fisher exact tests were used to analyze qualitative variables, depending on sample size. In all analyses, a significance level below 0.05 was established (95\% CI). Statistical software used included the Statistical Package for the Social Sciences (SPSS 19.0; Chicago, IL, USA) and "R" for Windows [12].

\section{RESULTS}

\section{Patients}

A total of 39 patients completed this follow-up extension study and received study medication throughout. Data were available for 27 males (69.2\%) and 12 females (30.8\%). Thirty-eight patients had idiopathic GHD, one with multiple deficiencies.

Patient characteristics on entry to the followup study (i.e., end of the phase III trial) are shown in Table 1. Mean (SD) age was 12.5 (2.7) years, mean height was $144.8(13.9) \mathrm{cm}$, and mean $\mathrm{HV}$ was $5.7(2.8) \mathrm{cm} /$ year. The median (range) dose of Omnitrope $^{\circledR}$ used at the beginning of the follow-up study was $1.03(0.80-1.40) \mathrm{mg} /$ week. There was no history of concomitant conditions, apart from two male patients (5.1\%) with concomitant heart disease. All patients who initially entered the phase III study were naïve to rhGH treatment. In the initial trial, the mean (SD) duration of $\mathrm{rhGH}$ treatment was 3.7 (1.0) years.

\section{Efficacy}

By the end of the follow-up period, mean height had increased by $+16.7 \mathrm{~cm}$ from baseline (end of the phase III study; Table 2). In males, mean height had increased by $+18.9 \mathrm{~cm}$ and in females by $+11.6 \mathrm{~cm}$ (Table 2 ). The difference of height increase between males and females did not reach statistical significance $(P=0.097)$.

Mean changes in HSDS and $\mathrm{HV}$ are illustrated in Figs. 1, 2, respectively. At the start of the follow-up study, HSDS initially increased and subsequently decreased gradually over time. Nonetheless, mean HSDS improved by +0.04 in males and +0.40 in females by the end of the follow-up period (Table 2). By the end of the study, mean (SD) $\mathrm{HV}$ decreased from an initial value of 5.7 (2.8) cm/year to 4.1 (3.1) cm/year (Fig. 2).

In the original study, which was conducted over 5 years, the $\mathrm{FH}_{\text {pro }}$ increased from baseline values of $157.6 \pm 3.3 \mathrm{~cm}$ (males) and 
Table 1 Patient characteristics at study entry (end of the phase III trial)

\begin{tabular}{llll}
\hline Characteristic & Males $(\boldsymbol{n}=\mathbf{2 7})$ & Females $(\boldsymbol{n}=\mathbf{1 2})$ & Total $(\boldsymbol{n}=\mathbf{3 9})$ \\
\hline Chronological age [years, mean (SD)] & $12.5(2.8)$ & $12.7(2.7)$ & $12.5(2.7)$ \\
Chronological age at onset of puberty [years, mean (SD)] & $12.9(1.2)$ & $11.9(1.7)^{\mathrm{a}}$ & $12.6(1.4)$ \\
Height [cm, mean (SD)] & $145.1(14.3)$ & $144.1(13.3)$ & $144.8(13.9)$ \\
Height SDS [mean (SD)] & $-1.11(0.69)$ & $-1.26(0.50)$ & $-1.16(0.63)$ \\
HV [cm/year, mean (SD)] & $5.9(2.7)$ & $5.4(3.0)$ & $5.7(2.8)^{\mathrm{c}}$ \\
Pubertal (Tanner) stage [n (\%)] & & & \\
I & $11(40.7)$ & $2(16.7)$ & $13(33.3)$ \\
II & $5(18.5)$ & $5(41.7)$ & $10(25.5)$ \\
III & $4(14.8)$ & $0(0.0)$ & $4(10.3)$ \\
IV & $5(18.5)$ & $3(25.0)$ & $8(20.5)$ \\
V & $2(7.4)$ & $2(7.4)$ & $4(10.3)$ \\
Concomitant conditions & & & $2(5.1)$ \\
Cardiovascular disease $[n(\%)]^{\mathrm{b}}$ & $2(7.4)$ & $0(0.0)$ & \\
\hline
\end{tabular}

$H V$ height velocity, $S D$ standard deviation, $S D S$ standard deviation score

${ }^{a} P=0.043$ for males versus females

b Percentages are calculated relative to each gender and then for the overall population (total column)

c Two patients had missing data for HV

Table 2 Adult height at the end of the follow-up study

\begin{tabular}{|c|c|c|c|}
\hline Characteristic [mean (SD)] & Males $(n=25)$ & Females $(n=11)$ & Total $(n=36)^{\mathrm{a}}$ \\
\hline Adult height $(\mathrm{cm})$ & $165.5(7.8)$ & $157.6(3.2)$ & $163.1(7.6)$ \\
\hline HSDS (adult height) & $-1.07(0.52)$ & $-0.86(0.72)$ & $-1.01(0.59)$ \\
\hline $\begin{array}{l}\text { Difference between height at follow-up study entry and } \\
\text { adult height }(\mathrm{cm})\end{array}$ & $\begin{aligned} 18.9 & (11.8) \\
(P & <0.001)\end{aligned}$ & $\begin{array}{l}11.6(12.0) \\
\quad(P<0.001)\end{array}$ & $\begin{aligned} 16.7 & (12.2) \\
(P & <0.001)\end{aligned}$ \\
\hline $\mathrm{FH}_{\text {pro }}$ after 5 years of treatment ${ }^{\mathrm{b}}$ & $167.5(3.3)$ & $157.7(1.6)$ & $\mathrm{n} / \mathrm{a}$ \\
\hline
\end{tabular}

$F H_{\text {pro }}$ projected final height, $n / a$ data not available, $S D$ standard deviation, $S D S$ standard deviation score

a Two patients have not yet reached adult height and remain in treatment; adult height in one patient could not be measured

b Data from López-Siguero et al. [11]

$146.4 \pm 3.0 \mathrm{~cm}$ (females) to $167.5 \pm 3.3 \mathrm{~cm}$ (males) and $157.7 \pm 1.6 \mathrm{~cm} \quad$ (females), respectively. These values represent an ultimate mean gain of $12-18 \mathrm{~cm}$ in the patients' $\mathrm{FH}_{\text {pro }}[11]$. An analysis of the 'real- life' final height values achieved by the end of this follow-up study revealed that these values, $165.5 \pm 7.8 \mathrm{~cm}$ (males) and $157.6 \pm 3.2 \mathrm{~cm}$ (females), closely reflected the $\mathrm{FH}_{\text {pro }}$ of the original trial (Table 2). 


\section{Safety}

At the end of the follow-up period, most patients had discontinued treatment, mainly due to reaching adult height/physician decision. The reasons for study discontinuation are presented in Table 3. Two male patients have still not yet reached adult height and remain in treatment at the end of this study. There were no treatmentrelated AEs reported in any of the patients enrolled in this long-term follow-up.

\section{Treatment Switches and Dose Adjustments During GH Therapy}

All patients started treatment with Omnitrope ${ }^{\circledR}$. In 9 cases $(23.1 \%)$, a switch in treatment was performed to different rhGH formulations: six patients $(15.4 \%)$ switched to Genotonorm ${ }^{\circledR}$ (Pfizer), one to Saizen ${ }^{\circledR}$ (Merck Serono), one to Norditropin $^{\circledR}$ SimpleXx ${ }^{\circledR}$ (Novo Nordisk), and in one case the new formulation was not specified. These formulation switches were related to ongoing changes in medical prescription practices and to the

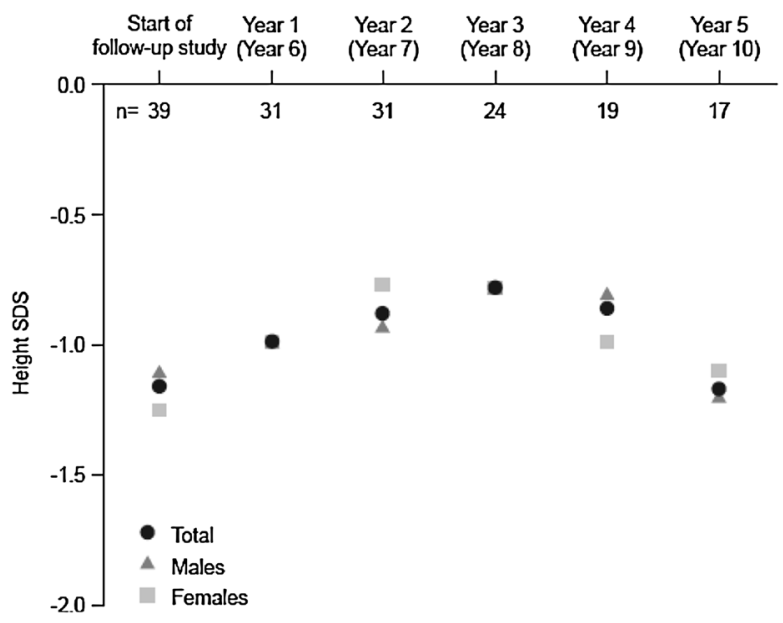

Fig. 1 Mean height standard deviation score (SDS) of children with growth hormone deficiency during longterm treatment with biosimilar recombinant human growth hormone implementation of new tenders in the participating hospitals.

All dose adjustments during the long-term follow-up consisted of dose increments to reflect changes in body weight.

\section{DISCUSSION}

The main objective of this long-term, retrospective follow-up study was to collect and analyze data on adult height in a cohort of Spanish children with GHD who received treatment with Omnitrope ${ }^{\circledR}$. The results for all the auxological parameters evaluated (height, HSDS, and HV) indicate that rhGH therapy elicited a positive growth response and led to normalization of height parameters.

In the initial phase III trial, the $\mathrm{FH}_{\text {pro }}$ values were an average height gain of $12-18 \mathrm{~cm}$, leading to final adult height of $157.7 \mathrm{~cm}$ for females and $167.5 \mathrm{~cm}$ for males [11]. At the end of this follow-up extension study, the average height gain was $11.6 \mathrm{~cm}$ for females and $18.9 \mathrm{~cm}$ for males, and the mean adult height achieved was $157.6 \mathrm{~cm}$ in females and $165.5 \mathrm{~cm}$

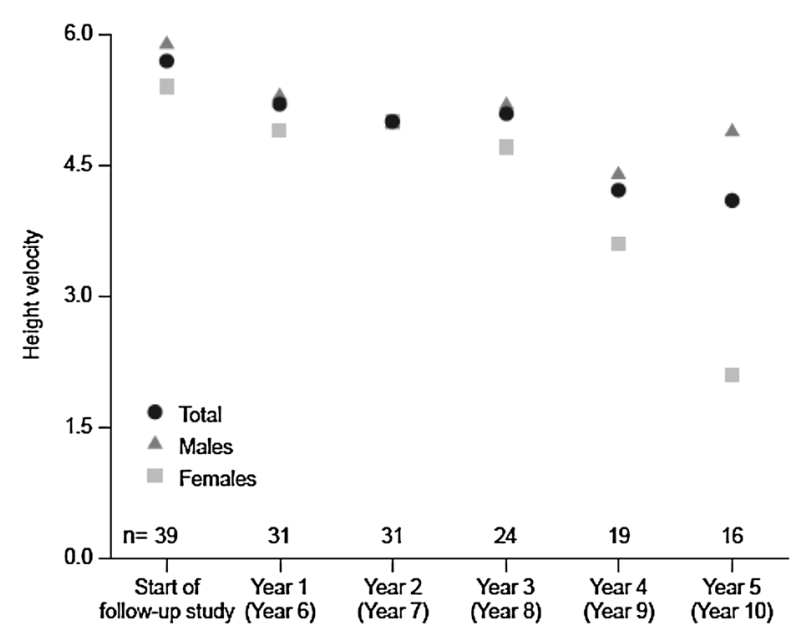

Fig. 2 Mean height velocity ( $\mathrm{cm} /$ year) of children with growth hormone deficiency during long-term treatment with biosimilar recombinant human growth hormone 
Table 3 Reasons for rhGH treatment discontinuation

\begin{tabular}{llll}
\hline Reason for discontinuation $[\boldsymbol{n}(\%)]^{\mathbf{a}}$ & $\begin{array}{l}\text { Males } \\
(\boldsymbol{n}=\mathbf{2 7})\end{array}$ & $\begin{array}{l}\text { Females } \\
(\boldsymbol{n}=\mathbf{1 2})\end{array}$ & $\begin{array}{l}\text { Total } \\
(\boldsymbol{n}=\mathbf{3 7})^{\mathbf{b}}\end{array}$ \\
\hline $\begin{array}{l}\text { Meeting criteria for ending treatment (reaching adult height) } \\
\text { Individual decision }\end{array}$ & $18(66.7)$ & $10(83.3)$ & $28(75.7)$ \\
$\begin{array}{l}\text { Non-renewal of prescribed medication by the local health } \\
\text { authority }\end{array}$ & $4(100)$ & $0(0.0)$ & $3(8.1)$ \\
\begin{tabular}{l} 
Poor tolerance or adverse events \\
\hline
\end{tabular} & $0(0.0)$ & $0(0.0)$ & $0(0.0)$ \\
\hline
\end{tabular}

${ }^{a}$ Percentages are calculated relative to each gender and then for the overall population (total column)

b Two male patients have not yet reached adult height and remain in treatment

in males, with a total HSDS of -1.01 (0.59). These values closely mirror the projected height values of the initial trial. Furthermore, in a contemporary series of 99 patients with isolated GHD (López-Siguero, data on file) the target height was -1.37 SDS.

While the final heights achieved by the patients in this study are lower than the current national averages, they are within the accepted 'normal' ranges for the adult Spanish population [13].

Similarly to the original 5-year study, HSDS continued to increase gradually during the first part of this follow-up study [11]. However, after 3 years HSDS started to decrease. Most of the patients followed were already decreasing their $\mathrm{HV}$ and all of them had achieved their peak height velocity previously.

Other factors that may have contributed to the slow down of HSDS and HV may be that some patients needed to receive a higher dose of rhGH. While the doses were increased for certain patients, perhaps more patients needed a dose increment. In addition, HSDS and HV may have slowed down as patients started to mature and reach their adult height.

Taken together, the results from this followup study demonstrate that rhGH treatment is effective and leads to notable improvements in all height parameters in children with GHD.
These findings are in line with other studies reporting that rhGH replacement therapy leads to normalization of height during childhood and also to near-normal adult height within the corresponding target range [4, 14, 15]. Furthermore, it has been proven that rhGH has beneficial effects on body composition and metabolism throughout adult life [14, 15].

Although during the study, $23 \%$ of patients switched to another rhGH product, due to administrative issues, the data reveal that the adult height is above the Spanish adult height average in more than $50 \%$ of subjects.

In terms of safety, there were no drug-related AEs in any patients over the course of the follow-up period. This favorable safety profile for biosimilar rhGH is also consistent with previous studies reporting a positive risk: benefit ratio for rhGH in children with GHD $[16,17]$.

This study had some inherent limitations, i.e., it was a multicenter, observational, retrospective study with a limited number of patients. The investigators were not required to perform any specific tests or evaluations as part of the study and additional data were not routinely collected. It would have been of interest to have more data on certain parameters such as parental height, age and height at the onset of puberty; duration of 
puberty; height gain during puberty; bone age; weight/BMI; mean exposure to study drug, and glucose parameters. In addition, no data were recorded that allow the calculation of the rhGH dose $/ \mathrm{kg} /$ day.

Moreover, $44.3 \%$ (31) of the patients included in the phase III clinical trial were lost to follow-up. The reason for this relates to patients reaching adulthood, ending rhGH therapy, and leaving pediatric clinical assistance being therefore impossible to contact. Of all contacted patients (40), only one denied consent to use clinical data.

Nevertheless, this study provides some valuable data on the adult height achieved by Spanish children with GHD following longterm biosimilar rhGH treatment.

Although the follow-up study did not include in the protocol any measure of compliance, as in standard clinical practice the adherence of patients to treatment with rhGh was evaluated through the clinical history and the records of distribution of the drug by the hospital pharmacy, which provides an insight into treatment adherence by the patients.

It seems that in Spain most patients are willing to adhere to rhGH treatment until they reach their adult height, and that changes in medication are sometimes influenced by the local health authorities.

Furthermore, this study depicts the longest follow-up period to date of patients treated with Omnitrope ${ }^{\circledR}$, confirming the long-term efficacy and safety of this treatment.

\section{CONCLUSION}

The results of this follow-up study demonstrate that children with GHD can be safely and effectively treated with Omnitrope ${ }^{\circledR}$ until they reach their adult height. The adult height values achieved are within the expected ranges for the normal adult population.

\section{ACKNOWLEDGMENTS}

This study and the associated article processing charges were funded by Sandoz Biopharmaceuticals. Medical writing assistance was provided by Sandra Cuscó PhD of Spirit Medical Communications Ltd, funded by Sandoz International GmbH. All named authors meet the International Committee of Medical Journal Editors (ICMJE) criteria for authorship for this manuscript, take responsibility for the integrity of the work as a whole, and have given final approval for the version to be published. All authors had full access to all the data in this study and take complete responsibility for the integrity of the data and accuracy of the data analysis.

Conflict of interest. Victoria Borrás Pérez, Juan Pedro López-Siguero, Gabriela Martínez, Raquel Corripio, Juan Manuel Fernández, Jose Ignacio Labarta, Marta Ferrer, Nuria Cabrinety, Marta Ramon-Krauel, Jordi Bosch, and Rafael Espino have no conflicts of interest. Pablo Prieto has received congress support (Sociedad Española de Endocrinología Pediátrica 2014) from Pfizer. Margarida Palla Garcia is an employee of Sandoz Biopharmaceuticals, Madrid, Spain. Francisco Jose Rebollo is an employee of Sandoz Biopharmaceuticals.

Compliance with ethics guidelines. Written informed consent was obtained from the patients or their legal representatives. The study was conducted according to the principles of the Declaration of Helsinki and adhered to the ICH Harmonized Guidelines for Good Clinical Practice. In addition, the study 
was monitored and approved by an Independent Ethics Committee.

Open Access. This article is distributed under the terms of the Creative Commons Attribution Noncommercial License which permits any noncommercial use, distribution, and reproduction in any medium, provided the original author(s) and the source are credited.

\section{REFERENCES}

1. Hindmarsh PC, Dattani MT. Use of growth hormone in children. Nat Clin Pract Endocrinol Metab. 2006;2:260-8.

2. Reh CS, Geffner ME. Somatotropin in the treatment of growth hormone deficiency and Turner syndrome in pediatric patients: a review. Clin Pharmacol. 2010;2:111-22.

3. Baroncelli GI, Saggese G. Effect of GH treatment on bone mass in children with GH deficiency. J Endocrinol Invest. 2005;28:23-7.

4. Reiter EO, Price DA, Wilton P, et al. Effect of growth hormone $(\mathrm{GH})$ treatment on the near-final Height of 1,258 patients with idiopathic GH deficiency: analysis of a large international database. J Clin Endocrinol Metab. 2006;91:2047-54.

5. Balercia G, Giovannini L, Paggi F, et al. Growth hormone deficiency in the transition period: body composition and gonad function. J Endocrinol Invest. 2011;34:709-15.

6. European Medicines Agency 2008. Omnitrope ${ }^{\circledR}$ European Public Assessment Report 2008. Available from: http://www.ema.europa.eu/docs/en GB/document_library/EPAR_-_Scientific_Discussion/ human/000607/WC500043692.pdf. Accessed Sept 1, 2014.

7. European Medicines Agency 2011. Omnitrope ${ }^{\circledR}$ Summary of Product Characteristics 2008. Available from: http://www.ema.europa.eu/docs/en_ GB/document_library/EPAR_-_Product_Information/ human/000607/WC500043695.pdf. Accessed Sept 1, 2014.
8. Romer T, Saenger P, Peter F, et al. Seven years of safety and efficacy of the recombinant human growth hormone Omnitrope in the treatment of growth hormone deficient children: results of a phase III study. Horm Res. 2009;72:359-69.

9. Pfäffle R, Schwab KO, Marginean O, et al. Design of, and first data from, PATRO children, a multicentre, noninterventional study of the long-term efficacy and safety of Omnitrope ${ }^{\circledR}$ in children requiring growth hormone treatment. Ther Adv Endocrinol Metab. 2013;4:3-11.

10. Schwarz HP, Birkholz-Walerzak D, Szalecki M, et al. One-year data from a long-term phase IV study of recombinant human growth hormone in short children born small for gestational age. Biol Ther. 2014;4:1-13.

11. López-Siguero J, Borrás Pérez MV, Balser S, et al. Long-term safety and efficacy of the recombinant human growth hormone Omnitrope ${ }^{\circledR}$ in the treatment of Spanish growth hormone deficient children: results of a phase III study. Adv Ther. 2011;28:879-93.

12. R Core Team. R: a language and environment for statistical computing. Available from: www.cran.rproject.org.

13. Sánchez-González E, Carrascosa Lezcano A, Fernández García JM, et al. Spanish growth studies: the current situation, their effectiveness and recommendations for their use. An Pediatr (Barc). 2011;74(e1-193):e16.

14. Kirk J. Indications for growth hormone therapy in children. Arch Dis Child. 2012;97:63-8.

15. Inzaghi E, Cianfarani S. The challenge of growth hormone deficiency diagnosis and treatment during the transition from puberty into adulthood. Front Endocrinol (Lausanne). 2013;4:34.

16. Bell J, Parker KL, Swinford RD, et al. Long-term safety of recombinant human growth hormone in children. J Clin Endocrinol Metab. 2010;95:167-77.

17. Divall SA, Radovick S. Growth hormone and treatment controversy; long term safety of $\mathrm{rGH}$. Curr Pediatr Rep. 2013;1:128-32. 